\title{
ÁGUA E SEUS INSTRUMENTOS LEGAIS DE PROTEÇÃO
}

\author{
U. G. F. Tamarindo* e J. C. Forti \\ UNESP - Univ Estadual Paulista, Campus de Tupã, SP, Brasil
}

\section{RESUMO}

O Brasil é naturalmente privilegiado com grandes rios e vegetações em seu território ${ }^{1}$, todavia, ao longo das últimas décadas, o seu maior patrimônio, a água doce, está sendo seriamente comprometido. Nessa ordem, é fato que a água nunca foi muito respeitada, talvez por ser gratuita e abundante. Entretanto, a situação atual de escassez de água em muitas regiões do País somada ao mau uso da terra e demais recursos naturais têm produzido, além de fortes alterações climáticas, importantes mudanças na economia e na sociedade em geral. A grave seca hoje vivenciada principalmente no Sudeste e Centro-Oeste do Brasil, bem como o excesso de chuvas e enchentes em outras partes do País deixa evidente tal advertência.

O Brasil está vulnerável a todas essas alterações climáticas. E em relação à água, se não houver mudanças concretas no uso o resultado em pouco tempo será catastrófico para todos. Não se pode conceber a permanência desse estado atual de inércia ambiental em relação às águas. As gerações atuais têm a obrigação de conhecer e, sobretudo colocar em prática as tutelas legais de proteção aos ecossistemas, notadamente das águas. E como afirmam Maude Barlow e Tony Clarke, "se não mudarmos logo nossa relação com a água e com os ecossistemas que a mantêm, toda a nossa riqueza e conhecimento não terão sentido algum"2.

A legislação nacional e internacional estabelecem meios de proteção à água, notadamente sob a perspectiva de que esta pode ser sujeito de direitos. Este artigo, portanto, apresenta uma visão geral das tutelas legais de proteção à água.

Palavras-chave: água, proteção, escassez, instrumentos legais de proteção.

\section{WATER AND YOUR PROTECTION LEGAL INSTRUMENTS}

\begin{abstract}
Brazil is naturally blessed with great rivers and vegetation in its territory, however, over the past decades, its greatest asset, fresh water, is being seriously compromised. It is a fact that the water was never very respected, perhaps because it is free and plentiful. However, the current situation of water scarcity in many regions of the country coupled with the misuse of land and other natural resources have produced, in addition to strong climate changes, major changes in the economy and society in general. Severe drought in the Southeast and Midwest regions of Brazil, as well as the excessive rains and floods in other parts of the country makes clear such a warning.

\footnotetext{
*ubirajara@fltadvocacia.com.br

${ }^{1}$ Há estudos apontando que o Brasil possui aproximadamente $12 \%$ da disponibilidade mundial de recursos hídricos, que é de 1,5 milhões de m3 s-1 (Shiklomanov et al. 2000). Shiklomanov, I.A., Shiklomanov, A.I., Lammers, R.B., Peterson, B.J. \& Vorosmarty, C.J. 2000. The dynamics of river water infl ow to the Arctic Ocean. In: Lewis, E.L., Jones, E.P., Prowse, T.D. \& Wadhams, P. (eds) The freshwater budget of the Arctic Ocean. Kluwer Academic Publishers, Dordrecht. p. 281-296

${ }^{2}$ BARLOW, MAUDE e CLARKE, TONY. Ouro Azul: como as grandes corporações estão se apoderando da água doce do nosso planeta. Tradução de Andreia Nastri. Tradução de atualizações de Natália Coutinho Mira de Assumpção. São Paulo: Editora M. Books do Brasil, 2003.
} 
Brazil is vulnerable to all these climate change. And in relation to water, there is no practical change in use will soon result in catastrophic for everyone. We cannot conceive the permanence of this current state of environmental inertia in relation to water. Current generations have an obligation to know and, above all, implementing the legal guardianship for the protection of ecosystems, especially water. And as Maude Barlow and Tony say Clarke, "is not soon change our relationship with water and ecosystems that remain, all our wealth and knowledge will have no meaning."

National and international law establish safeguards to water, especially from the perspective that this can be a subject of rights. This article therefore presents an overview of the legal guardianship of protection to water.

Keywords: water, protection, scarcity, legal instruments

\section{INTRODUÇÃO}

O aumento populacional, o crescimento econômico, o aumento na demanda por energia e, sobretudo ao mau uso dos recursos naturais têm exigido de todas as nações a implementação de políticas públicas concernentes ao uso racional e sustentável da água. Não basta apenas a mobilização governamental nessa direção. A participação efetiva das empresas, organizações não governamentais e, sobretudo da população ${ }^{3}$ na concretização de práticas sustentáveis são essenciais para o processo de proteção ao meio ambiente ${ }^{4}$, notadamente das águas.

\footnotetext{
3 “'Ao explorar a propriedade com a agricultura ou criação de animais, mesmo objetivando auferir o seu sustento e de sua família, também é obrigação da parte autora a defesa ecológica, mormente porque a própria atividade econômica tem como pressuposto essa proteção (art. 170, $\mathrm{CF}$ ). $\mathrm{O}$ direito de propriedade não é uma cláusula aberta para a prática de atividades que não se coadunam com o interesse coletivo ao meio ambiente sadio e sustentável". Supremo Tribunal Federal - ARE: 805414 RS, Relator: Min. GILMAR MENDES, Data de Julgamento: 15/04/2014, Data de Publicação: DJe-077/24/04/2014.

4 “A incolumidade do meio ambiente não pode ser comprometida por interesses empresariais nem ficar dependente de motivações de índole meramente econômica, ainda mais se tiver presente que a atividade econômica, considerada a disciplina constitucional que a rege, está subordinada, dentre outros princípios gerais, àquele que privilegia a 'defesa do meio ambiente' (CF, art. 170, VI), que traduz conceito amplo e abrangente das noções de meio ambiente natural, de meio ambiente cultural, de meio ambiente artificial (espaço urbano) e de meio ambiente laboral". (Supremo Tribunal Federal - Pleno, ADIn/MC 3540-1, Rel. Min. Celso de Mello).
}

Olhando para o passado, verifica-se que a preocupação com o meio ambiente não é assunto novo no Brasil. A propósito, José Bonifácio de Andrade e Silva, conhecido como "Patriarca da Independência", e que ocupou o cargo de Ministro e Senador do Império do Brasil, à sua época já advertia que ${ }^{5}$ :

"A natureza fez tudo a nosso favor, nós, porém, pouco ou nada temos feito a favor dela. Nossas terras estão ermas e as poucas que temos roteado são mal cultivadas, porque o são por braços indolentes e forçados. Nossas numerosas minas, por falta de trabalhadores ativos e instruídos, estão desconhecidas ou mal aproveitadas. Nossas preciosas matas vão desaparecendo, vítimas do fogo, do machado destruidor, da ignorância e do egoísmo. Nossos montes e encostas se vão escalvando diariamente e, com o andar do tempo, certamente faltarão cair chuvas fecundantes, para favorecerem a vegetação e alimentarem nossas fontes e rios, sem o que, o nosso belo Brasil, em menos de dois séculos, ficará reduzido aos paramos e desertos áridos da Líbia. Virá então este dia, terrível e falta, e que a ultrajada natureza se ache vingada de tantos erros e crimes cometidos por nós humanos".

Não há dúvidas, portanto, da atualidade do discurso proclamado há

\footnotetext{
${ }^{5}$ Palavras do Ministro e Senador do Império do Brasil, José Bonifácio de Andrada e Silva, representando o primeiro movimento ambientalista brasileiro - apud MARTINS DA SILVA, Américo Luís, Direito do Meio Ambiente e dos Recursos Naturais, v. 3, Editora RT, 2006.
} 
quase 200 anos, deixando evidente que o desrespeito ao meio ambiente já era praxe no Brasil desde os tempos do Império.

Com efeito, somente na última década se percebeu no Brasil a necessidade de proteção legal na esfera governamental dos recursos hídricos. A legislação brasileira estabelece vários dispositivos de proteção às águas, os quais, de forma geral, serão abordados neste artigo.

\section{O DIREITO DAS ÁGUAS}

O tema água é um dos mais discutidos e relevantes do mundo contemporâneo. Neste sentido, os estudiosos apontam que o assunto será o próximo elemento deflagrador das grandes crises e conflitos mundiais (MILARÉ, pgs. 916).

Por seu turno, a preocupação com a preservação do meio ambiente, como adverte Ana Alice de Carli, "não deve - $e$ não pode - restringir-se à seara dos ambientalistas, biólogos, químicos, geólogos, ecologistas, hidrólogos e outros tantos estudiosos e pesquisadores que dedicam parcela de seu tempo para cuidar de assuntos relacionados com o Planeta Terra; profissionais, cujas vozes, durante décadas, soaram apenas como sussurros aos ouvidos dos demais atores sociais, eis que as questões ambientais, por longo tempo, foram preteridas em favor de interesses patrimoniais até mesmo na seara do Direito" (DE CARLI, p. 52/53).

Nessa ordem, destaca-se, de início, que a Constituição Federal brasileira, promulgada em 05 de outubro de 1988, estabeleceu em seu artigo 26, que incluemse entre os bens dos Estado: I - as águas superficiais ou subterrâneas, fluentes, emergentes e em depósito, ressalvadas, neste caso, na forma da lei, as decorrentes de obras da União.

O inciso, como adverte Édis Milaré (MILARÉ, pg. 929), abrange "todo o ciclo hidrológico terrestre, inclusive as águas subterrâneas e as águas nascentes (emergentes), assim como as fluentes (rios e córregos) e dormentes (em depósitos: lagos, lagoas e represas). Exclui apenas as represas decorrentes de obras da União. $O$ texto, como se vê, não faz qualquer limitação territorial, donde se conclui, originalmente, as águas são de domínio dos Estados.

A seu turno, o artigo 20 estabelece: "São bens da União (...) III - os lagos, rios e quaisquer correntes de água em terrenos de seu domínio, ou que banhem mais de um Estado, sirvam de limites com outros países, ou se estendam a território estrangeiro ou dele provenham, bem como os terrenos marginais e as praias fluviais; (...) VI - o mar territorial; (...) VIII - os potenciais de energia hidráulica; (...)”.

Prossegue Édis Milaré afirmando que: "O inc. III trata das águas interiores $e$ define-as não de forma geral como as águas estaduais, mas de forma mais específica, referindo-se a lagos, rios $e$ correntes de água em situações determinadas: limítrofes com Estados ou com outro país, ou situadas em mais de um Estado ou país. Em suma, são da União as águas interiores superficiais que não se contenham no território de um Estado. As águas subterrâneas são sempre estaduais, independentemente da extensão do aquífero ${ }^{6}$.

$O$ inc. VI inclui, entre os bens da União, o mar territorial. As águas marítimas são sempre da União.

$O$ inc. VIII, seguindo a tradição de nosso Direito das águas, reservou à União o domínio dos potenciais de energia hidráulica, onde quer que se situem: em águas da própria União ou em águas dos estados" (MILARÉ, pgs. 929, 930).

Importar registrar ainda que águas de domínio municipal já não existem desde a Constituição brasileira de 1946.

Estas considerações preliminares são importantes para que possamos delimitar a competência e responsabilidade de cada ente da federação na proteção dos recursos hídricos.

\footnotetext{
6 "Veja-se, por exemplo, o caso do Aquífero Guarani, que se espalha pelo subsolo de oito Estados (Mato Grosso, Mato Grosso do Sul, Goiás, Minas Gerais, São Paulo, Paraná, Santa Catarina e Rio Grande do Sul)".
} 
Pois bem. $\mathrm{O}$ arcabouço legal brasileiro referente ao direito de águas está consubstanciado em um sistema de normas e princípios que regem a forma pela qual se desenvolvem as políticas públicas de gestão dos recursos. Segundo Cid Tomanik Pompeu $^{7}$, o direito de águas consubstancia uma área específica do Direito, e pode ser conceituado como o "conjunto de princípios e normas jurídicas que disciplinam o domínio, o uso, o aproveitamento a conservação $e \quad a$ preservação das águas, assim como a defesa contras suas danosas consequências".

A Constituição brasileira, por sua vez, estabeleceu em seu artigo 22, inciso IV, competir privativamente à União legislar sobre águas. Esse dispositivo é complementado por legislação ordinária e resoluções que disciplinam a matéria. Embora a competência para legislar sobre águas seja privativa da União, isso não significa que os Estados, Municípios e o Distrito Federal não possam legislar sobre proteção ao meio ambiente, o que inclui as águas. Com efeito, os artigos $23^{8}$, incisos $\mathrm{VI}^{9}, \mathrm{VII}^{10}, \mathrm{XI}^{11}$ e $24^{12}$, incisos $\mathrm{VI}^{13}$ e VIII $^{14}$, ambos da Constituição brasileira, conferem essa legitimidade. E no tocante aos recursos hídricos, alguns Estados, por exemplo, já elaboraram leis: São Paulo Lei $n^{\circ} 7.663$, de 30/12/1992; Ceará - Lei $\mathrm{n}^{\circ}$ 11.996, de 24/7/1992; Minas Gerais Lei $\mathrm{n}^{\circ} 11.504$, de 20/06/1994; Rio Grande do Sul - Lei $\mathrm{n}^{\circ}$ 10.350, de 10/12/1994;

\footnotetext{
7 Apub DE CARLI, Ana Alice, A Água e Seus Instrumentos de Efetividade, pg. 53/54, Editora Millennium, 2013

8 É competência comum da União, dos Estados, do Distrito Federal e dos Municípios:

9 - proteger o meio ambiente e combater a poluição em qualquer de suas formas;

10 - preservar as florestas, a fauna e a flora;

11 - registrar, acompanhar e fiscalizar as concessões de direitos de pesquisa e exploração de recursos hídricos e minerais em seus territórios;

12 Compete à União, aos Estados e ao Distrito Federal legislar concorrentemente sobre:

13 - florestas, caça, pesca, fauna, conservação da natureza, defesa do solo e dos recursos naturais, proteção do meio ambiente e controle da poluição;

14 - responsabilidade por dano ao meio ambiente (...)
}

Bahia - Lei $n^{\circ} 6.855$, de 12/05/1995, e Rio Grande do Norte - Lei $\mathrm{n}^{\circ}$ 1/7/1996 (MACHADO, p. 499).

Nesse contexto, o Supremo Tribunal Federal $^{15}$ - STF e o Superior Tribunal de Justiça $^{16}$ - STJ já reconheceram em diversos julgados que os Estados, Municípios e o Distrito Federal são competentes legislativamente para assegurar a proteção ambiental, valendo a pena a transcrição das seguintes ementas:

APELAÇÃO CÍVEL. CONSTITUCIONAL E ADMINISTRATIVO. MUNICÍPIO DE ERECHIM - VIGILÂNCIA SANITÁRIA. ABSTENÇÃO DE INTERDIÇÃO DE POÇO ARTESIANO CLANDESTINO. ÁGUA COMO UM BEM PÚBLICO. FISCALIZAÇÃO MUNICIPAL RESTRITA À SAÚDE PÚBLICA. APLICAÇÃO DOS ARTIGOS 23, II, 198, I E 200, I E II DA CONSTITUIÇÃO FEDERAL. COMPROVADA A POTABILIDADE DA ÁGUA. COMPETÊNCIA MUNICIPAL DE FISCALIZAÇÃO AFASTADA. LICENÇA PARA USO DA ÁGUA EM ZONA SERVIDA POR REDE PÚBLICA. COMPETÊNCIA DO ESTADO. MANDADO DE SEGURANÇA. DENEGAÇÃO DA ORDEM NA ORIGEM. APELAÇÃOO PROVIDA. SENTENÇA REFORMADA. 1. Diante da preocupação com a finitude da água, bem público e essencial à vida, foi instituída a Política Nacional de Recursos Hídricos, sendo um dos principais objetivos assegurar à atual e às futuras gerações a necessária disponibilidade de água, em padrões de qualidade adequados aos respectivos usos. 2. A Fiscalização Municipal, pois, no que concerne ao uso da água, está restrita, no âmbito de sua circunscrição, aos problemas relacionados à saúde pública, forte nos termos da Constituição Federal, arts. 23, II, 198, I e 200, I e II. 3. In casu, pois, ante a existência de prova da potabilidade da água, de todo incorreta a atuação do Município que acabou por avocar competência que não lhe foi atribuída. 4. É que as questões relacionadas à licença para uso da água de fonte alternativa de abastecimento em zona servida por rede pública é atribuição que compete ao Estado." 2. Os recorrentes, Município de Erechim e o Ministério Público Estadual, alegam violação do disposto nos artigos 23, II, VI e XI, e 225, caput, da Constituição do Brasil. Sustentam a competência administrativa do Município para exercer o poder de polícia em matéria ambiental. 3. O Ministério Público Federal, em parecer subscrito pelo Subprocurador-Geral da República Paulo de Tarso Braz Lucas, opinando pelo provimento do recurso, observou [fls. 404/405]: "Os recursos merecem conhecimento e provimento. É que a conclusão do acórdão

\footnotetext{
${ }^{15}$ www.stf.jus.br

${ }^{16}$ www.stj.jus.br
} 
recorrido, de que a fiscalização municipal no que concerne ao uso da água está restrita aos problemas relacionados à saúde pública, acabou por contrariar o art. 23, XI, da Constituição Federal, que confere competência comum aos entes federativos para registrar, acompanhar e fiscalizar as concessões de direitos de pesquisa e exploração de recursos hídricos e minerais em seus territórios. A Lei Maior não limitou o poder de polícia municipal às questões de saúde pública. Com razão o Parquet estadual ao afirmar que a fiscalização do município inclui também aspectos ambientais (fls. 335), in verbis: 'A fiscalização do município, dessa forma não fica restrita a questões concernentes à saúde pública, estendendo-se para todas as vicissitudes inerentes ao meio ambiente, na medida em que este conceito abrange os recursos hídricos. Nesse diapasão, a atuação municipal envolverá aspectos ambientais, a exemplo da destinação dos resíduos líquidos, da verificação da possibilidade de contaminação de todo lençol freático, do impacto da exploração da água subterrânea nos demais recursos ambientais, especialmente na vegetação em seu entorno e nos recursos minerais, etc.' E a jurisprudência do Supremo Tribunal Federal reconhece essa competência comum, tal como já ressaltado pelo Exmo. Sr. Min. Celso de Mello, em despacho proferido na AC $\mathrm{n}^{\circ} 1255 / \mathrm{RR}$, verbis: Sabemos que, no sistema constitucional brasileiro, a União, os Estados-membros, o Distrito Federal e os Municípios dispõem de competência para adotar medidas tendentes a assegurar a proteção ambiental, mesmo porque a preservação da (JOSÉ AFONSO DA SILVA, 'Direito Ambiental Constitucional', p. 75, item n. 8, $5^{\text {a }}$ ed., 2004, Malheiros) integridade do meio ambiente - além de representar direito fundamental que assiste à generalidade das pessoas - traduz obrigação político-jurídica indeclinável que se impõe a todas as esferas de poder, como esta Suprema Corte já teve o ensejo de reconhecer e proclamar:'- Todos têm direito ao meio ambiente ecologicamente equilibrado." 4. Adoto como razão de decidir os argumentos expendidos pelo Ministério Público Federal. Dou provimento aos recursos com fundamento no disposto no artigo 557, $\S 1^{\circ}$-A, do CPC. Inverto os ônus de sucumbência, ressalvada a hipótese de concessão de justiça gratuita. Publique-se. Brasília, 17 de novembro de 2009. Ministro Eros Grau - Relator - 1 (STF - RE: 596723 RS , Relator: Min. EROS GRAU, Data de Julgamento: 17/11/2009, Data de Publicação: DJe-228 - 04/12/2009)

ADMINISTRATIVO. POÇO ARTESIANO IRREGULAR. FISCALIZAÇÃO. OBJETIVOS E PRINCÍPIOS DA LEI DA POLÍTICA NACIONAL DE RECURSOS HÍDRICOS (LEI 9.433/97). COMPETÊNCIA COMUM DO MUNICÍPIO. 1. Hipótese em que se discutem os limites da competência fiscalizatória municipal relacionada à perfuração de poço artesiano e sua exploração por particular. 2. O Município autuou o recorrido e lacrou seu poço artesiano, por inexistência de autorização e descumprimento da legislação estadual que veda a exploração dos recursos hídricos, pelo particular,naquela área. 3 . $\mathrm{O}$ Tribunal de origem entendeu que a competência do Município para fiscalizar referese, exclusivamente, à proteção da saúde pública. Ocorre que a lacração do poço não decorreu dessa competência (a água é comprovadamente potável, sem risco para a saúde), mas sim por conta de descumprimento das normas que regem a exploração dos recursos hídricos, editadas pelo Estado. 4. Não há controvérsia quanto à legislação local, que, segundo o Ministério Público Estadual, veda a perfuração e a exploração de poço artesiano da área. 5. O acórdão recorrido fundamenta-se nas competências fixadas pela Lei da Política Nacional de Recursos Hídricos (Lei 9.433/97), ainda que interpretada à luz dos arts. 21, XIX, e 26, I, da Constituição Federal, o que atrai a competência do STJ. 6. A Lei 9.433/97, adotada pelo Tribunal de Justiça em suas razões de decidir, aponta claramente a competência dos Municípios para a gestão dos recursos hídricos (art. $1^{\circ}, \mathrm{VI}$ ) e para a "integração das políticas locais de saneamento básico, de uso, ocupação e conservação do solo e de meio ambiente com as políticas federais e estaduais de recursos hídricos" (art. 31). 7. Os arts. $1^{\circ}$, VI, e 31 da Lei da Política Nacional de Recursos Hídricos devem ser interpretados sob o prisma constitucional, que fixa a competência comum dos Municípios, relativa à proteção do meio ambiente e à fiscalização da exploração dos recursos hídricos (art. 23, VI e XI, da Constituição). 8. A Lei da Política Nacional de Recursos Hídricos significou notável avanço na proteção das águas no Brasil e deve ser interpretada segundo seus objetivos e princípios.9. Três são os objetivos dorsais da Lei 9.4433/97, todos eles com repercussão na solução da presente demanda: a preservação da disponibilidade quantitativa e qualitativa de água, para as presentes e futuras gerações; a sustentabilidade dos usos da água,admitidos somente os de cunho racional; e a proteção das pessoas e do meio ambiente contra os eventos hidrológicos críticos, desiderato que ganha maior dimensão em época de mudanças climáticas.10. Além disso, a Lei da Política Nacional de Recursos Hídricos apoia-se em uma série de princípios fundamentais, cabendo citar, entre os que incidem diretamente no litígio, o princípio da dominialidade pública (a água, dispõe a lei expressamente, é bem de domínio público), o princípio da finitude (a água é recurso natural limitado) e o princípio da gestão descentralizada e democrática.11. As águas subterrâneas são "recurso ambiental", nos exatos termos do art. $3^{\circ}, \mathrm{V}$, da Lei da Política Nacional do Meio Ambiente (Lei 6.938/81), o que obriga o intérprete, na solução de litígios associados à gestão de recursos hídricos, a fazer uma leitura conjunta dos dois textos legais, em genuíno exercício de diálogo das fontes. 12. É evidente que a perfuração indiscriminada e desordenada de poços artesianos tem impacto direto no meio ambiente e na disponibilidade de recursos hídricos para o restante da população,de hoje 
e de amanhã. Feita sem controle, também põe em risco a saúde pública, por ausência de tratamento, quando for de rigor. 13. Em síntese, o Município tem competência para fiscalizar a exploração de recursos hídricos, superficiais e subterrâneos, em seu território, o que lhe permite, por certo, também coibir a perfuração e exploração de poços artesianos, no exercício legítimo de seu poder de polícia urbanístico, ambiental, sanitário e de consumo. 14. Recurso Especial provido. (STJ - REsp: 994120 RS 2007/0234852-0, Relator: Ministro HERMAN BENJAMIN, Data de Julgamento: 25/08/2009, T2 - Data de Publicação: DJe $27 / 04 / 2011)$

Além disso, o artigo 225 da Constituição brasileira, rotineiramente citado nas decisões judiciais proferidas pelo Supremo Tribunal Federal em matéria ambiental, estabelece um sistema constitucional amplo de proteção ao meio ambiente, o que inclui as águas:

Art. 225. Todos têm direito ao meio ambiente ecologicamente equilibrado, bem de uso comum do povo e essencial à sadia qualidade de vida, impondo-se ao Poder Público e à coletividade o dever de defendê-lo e preservá-lo para as presentes e futuras gerações.

$\S \mathbf{1}^{\circ}$ - Para assegurar a efetividade desse direito, incumbe ao Poder Público:

I - preservar e restaurar os processos ecológicos essenciais e prover o manejo ecológico das espécies e ecossistemas;

II - preservar a diversidade e a integridade do patrimônio genético do País e fiscalizar as entidades dedicadas à pesquisa e manipulação de material genético;

III - definir, em todas as unidades da Federação, espaços territoriais e seus componentes a serem especialmente protegidos, sendo a alteração e a supressão permitidas somente através de lei, vedada qualquer utilização que comprometa a integridade dos atributos que justifiquem sua proteção;

IV - exigir, na forma da lei, para instalação de obra ou atividade potencialmente causadora de significativa degradação do meio ambiente, estudo prévio de impacto ambiental, a que se dará publicidade;

V - controlar a produção, a comercialização e o emprego de técnicas, métodos e substâncias que comportem risco para a vida, a qualidade de vida e o meio ambiente;

VI - promover a educação ambiental em todos os níveis de ensino e a conscientização pública para a preservação do meio ambiente;
VII - proteger a fauna e a flora, vedadas, na forma da lei, as práticas que coloquem em risco sua função ecológica, provoquem a extinção de espécies ou submetam os animais a crueldade.

$\$ \mathbf{2}^{\mathbf{0}}$ - Aquele que explorar recursos minerais fica obrigado a recuperar o meio ambiente degradado, de acordo com solução técnica exigida pelo órgão público competente, na forma da lei.

$\S 3^{\mathbf{0}}$ - As condutas e atividades consideradas lesivas ao meio ambiente sujeitarão os infratores, pessoas físicas ou jurídicas, a sanções penais e administrativas, independentemente da obrigação de reparar os danos causados.

\$ 4 ${ }^{\mathbf{0}}$ - A Floresta Amazônica brasileira, a Mata Atlântica, a Serra do Mar, o Pantanal Mato-Grossense e a Zona Costeira são patrimônio nacional, e sua utilização farse-á, na forma da lei, dentro de condições que assegurem a preservação do meio ambiente, inclusive quanto ao uso dos recursos naturais.

$\$ \mathbf{5}^{\mathbf{0}}$ - São indisponíveis as terras devolutas ou arrecadadas pelos Estados, por ações discriminatórias, necessárias à proteção dos ecossistemas naturais

$\S \mathbf{6}^{\mathbf{0}}$ - As usinas que operem com reator nuclear deverão ter sua localização definida em lei federal, sem o que não poderão ser instaladas.

$\mathrm{Na}$ sequência, destaca-se o Decreto Federal $n^{\circ} 24.643$, de 10 de julho de 1934, que instituiu o chamado "Código de água", onde fora consubstanciada a legislação básica brasileira de águas. Este código é o marco legal da administração dos recursos hídricos no País, e foi considerado durante muito tempo como uma das mais modernas e completas leis de proteção às águas já elaboradas, posto que as diretrizes nele constantes foram reproduzidas em diversos países como modelos a serem seguidos.

Sob o aspecto histórico, como leciona Édis Milaré, “a implementação do Código de água ficou a cargo de órgão federais, no que respeita às águas de domínio da União, e de órgãos estaduais, nas de domínio dos Estados. Na órbita federal, essa competência era do Departamento nacional de Águas $e$ Energia Elétrica - DNAEE, compartilhada com o Departamento nacional de Obras contra as Secas - DNOCS nas áreas sujeitas ao flagelo das secas. Os Estados 
também constituíram órgãos para aplicar o Código de Águas, e seus atos mais importantes eram as autorizações para a derivação de águas e as concessões para o aproveitamento de energia hidroelétrica, sendo que estas eram de exclusiva competência da União.

A gestão das águas limitava-se à gestão de sua quantidade, sem preocupação com sua qualidade. A isso acresce que a gestão da qualidade estava basicamente condicionada às concessões para aproveitamento hidroelétrico, tanto nas águas federais quanto nas estaduais.

$\mathrm{Na}$ década de 1970 surge a preocupação com a poluição em geral e, particularmente, das águas. Os Estados mais industrializados, especialmente São Paulo e Rio de Janeiro, passaram a legislar sobre o controle da poluição das águas, do ar e do solo. Vieram, assim, a controlar a poluição em todas as águas existentes em seus territórios, sem limitação quanto a seu domínio" (MILARÉ, pg. 922/923).

Merece importante destaque ainda nessa trajetória o Código Florestal brasileiro, que atualmente está regulado pela Lei Nacional $\mathrm{n}^{\circ} 12.651$, de 25 de maio de 2012, e que por sua vez instituiu normas gerais sobre onde e de que forma $o$ território brasileiro pode ser explorado ao determinar as áreas de vegetação nativa que devem ser preservadas e quais as regiões que devem ser preservadas e quais regiões são legalmente autorizadas a receber os tipos de produção rural. Além disso, o Código Florestal brasileiro estabelece normas gerais sobre a ação governamental de proteção e uso sustentável de florestas, consagrando o compromisso do País com a compatibilização e harmonização entre o uso produtivo da terra e a preservação da água, do solo e da vegetação.

Desde a sua edição, em 1967 (Lei $\mathrm{n}^{\circ}$ 4.771), o Código Florestal brasileiro vem sofrendo alterações visando dar concretude à Política Nacional de Saneamento, instituída por meio da Lei $\mathrm{n}^{\circ}$ 5.138, de 26/09/1967.
No atual Código Florestal, porém, o tema "água" ganhou importante atenção dos legisladores. A palavra 'água' é citada em 93 oportunidades. Daí já se denota a importância do tema para o diploma legal, embora não seja este propriamente dito um "código de águas""17.

Importante registrar ainda que o novo Código Florestal brasileiro tem como um de seus importantes princípios o fomento à pesquisa científica e tecnológica na busca da inovação para o uso sustentável da água.

No mais, a Lei Nacional $n^{\circ} 9.433$, de 8 de janeiro de 1997, conhecida como "Lei das Águas", instituiu a "Política Nacional de Recursos Hídricos" e o "Sistema Nacional de Gerenciamento de Recursos Hídricos", regulamentando, assim, o inciso XIX do artigo $21^{18}$ da Constituição Federal.

Além desses dispositivos normativos, pode-se relacionar ainda as seguintes leis, decretos e resoluções de proteção às águas:

\section{LEIS FEDERAIS:}

Lei $n^{\text {o }}$ 5.357, de 07/12/67: Estabelece penalidades para embarcações e territoriais Marítimas ou fluviais que lançaram detritos ou óleo em águas brasileiras;

Lei $n^{\circ}$ 5318, de 26 de setembro de 1967: Institui a Política Nacional de Saneamento e cria o Conselho Nacional de Saneamento;

Lei $n^{\text {o }}$ 6.938, de 31/08/81: Dispõe a Política Nacional do Meio Ambiente;

Lei $n^{\text {o }}$ 7.661, de 16/05/88: Institui o Plano Nacional de Gerenciamento Costeiro;

Lei $\mathrm{n}^{\circ}$ 12.651, de 25 de maio de 2012: Institui o Código Florestal.

\section{DECRETOS FEDERAIS:}

Decreto $\mathrm{n}^{\circ} \quad \mathbf{8 9 . 3 3 6}$, de 31/01/84: Dispõe sobre as reservas Ecológicas e áreas de relevante Interesse Ecológico;

${ }^{17}$ O Código de água, estabelecido pelo Decreto Federal n. ${ }^{\circ} 24.643$, de 10 de julho de 1934 , consubstancia a legislação básica brasileira de águas.

\footnotetext{
18 Art. 21. Compete à União: XIX - instituir sistema nacional de gerenciamento de recursos hídricos e definir critérios de outorga de direitos de seu uso
} 
Decreto no 99.274, de 06/06/90: Regulamenta a Lei n. ${ }^{\circ} 6.938$, sobre a Política Nacional do Meio Ambiente.

Decreto $\mathrm{n}^{0}$ 50.877, de 29 de junho de 1961: Dispõe sobre o lançamento de resíduos tóxicos ou oleosos nas águas interiores ou litorâneas do país e dá outras providências;

Decreto $n^{0}$ 78.171, de 2 de agosto de 1976: Dispõe sobre o controle e fiscalização sanitária das águas minerais destinadas ao consumo humano

\section{RESOLUÇÕES do CONAMA:}

Resolução $\quad n^{0} \quad$ 04, de 18/09/85: Define Reservas Ecológicas;

Resolução $\mathbf{n}^{\circ} \quad 20$, de 18/06/86: Classifica as águas segundo seus usos preponderantes.

\section{LEIS ESTADUAIS - SÃO PAULO}

Lei $n^{0} \quad 898$, de 18/12/75: Disciplina o uso do solo para a proteção dos mananciais, cursos e reservatórios de água e demais recursos hídricos de interesse da Região Metropolitana da Grande São Paulo;

Lei $n^{\text {o }}$ 997, de 31/05/76: Dispõe sobre controle da poluição do meio ambiente;

Lei $n^{\circ}$ 1172, de 17/11/76: Delimita as áreas de proteção relativas aos mananciais, cursos e reservatórios de água;

Lei $n^{\text {o }}$ 6.134, de 02/06/88: Dispõe sobre a preservação dos depósitos naturais de águas subterrâneos no Estado de São Paulo;

Lei $\mathrm{n}^{\mathrm{o}} \mathbf{7 . 6 6 3}$, de 30/12/91: Estabelece a Política de Recursos Hídricos;

Lei $n^{0}$ 7.750, de 31/03/92: Dispõe sobre a Política de Saneamento;

Lei $n^{\text {o }}$ 9.509, de 20/03/97: Dispõe sobre a Política Estadual do Meio Ambiente;

Lei $\mathrm{n}^{\mathrm{o}}$ 9.866, de 28/11/97: Diretrizes e normas para proteção e recuperação das Bacias hidrográficas dos mananciais de interesse Regional do Estado de São Paulo.

\section{DECRETOS}

SÃO PAULO

\section{ESTADUAIS}

Decreto $\mathrm{n}^{\text {o }}$ 9714, de 19/04/77: Aprova o Regulamento das Leis 898/75 e 1172/76;

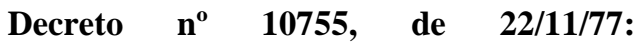
Dispõe sobre o enquadramento dos corpos de água receptores na classificação prevista no Decreto $8468 / 76$.

\section{TUTELA JUDICIAL DAS ÁGUAS}

Importante papel foi reservado ao Poder Judiciário na tutela e resolução dos conflitos ambientais, uma vez que é por meio dele que o Ministério Público, a Defensoria Pública, a Ordem dos Advogados do Brasil, a União, os Estados, o Distrito Federal, os Municípios, a autarquia, a empresa pública, a fundação, a sociedade de economia mista, a associação civil ou qualquer cidadão poderão exercer o direito constitucional de ação em defesa das águas ${ }^{19}$.

De início, registra-se que o inciso LXXIII, do artigo $5^{\circ}$, da Constituição brasileira, assegura importante instrumento de proteção às águas, ao garantir que qualquer cidadão é parte legítima para propor ação popular que vise a anular ato lesivo ao meio ambiente, ficando o autor, salvo comprovada má-fé, isento de custas judiciais e do ônus da sucumbência.

Este instrumento garante, portanto, que qualquer cidadão denuncie ao Poder Judiciário atos lesivos às águas ${ }^{20}$, bem como pleiteie nos termos do artigo $5^{\circ}$, $\S 4^{\circ}$, da Lei Nacional $n^{\circ} 4.717$, de 29 de junho de $1965^{21}$, a concessão de medida liminar para suspensão imediata da medida lesiva.

${ }^{19}$ Art. $5^{\circ}, \mathrm{XXXV}$, da CF/88.

20 ADMINISTRATIVO. AÇÃO POPULAR. INTERESSE DE AGIR. PROVA PERICIAL. DESNECESSIDADE. MATÉRIA CONSTITUCIONAL. (...) 2. As condições gerais da ação popular são as mesmas para qualquer ação: possibilidade jurídica do pedido, interesse de agir e legitimidade para a causa. 3. A ação popular pode ser ajuizada por qualquer cidadão que tenha por objetivo anular judicialmente atos lesivos ou ilegais aos interesses garantidos constitucionalmente, quais sejam, ao patrimônio público ou de entidade de que o Estado participe, à moralidade administrativa, ao meio ambiente e ao patrimônio histórico e cultural. 4. A ação popular é o instrumento jurídico que deve ser utilizado para impugnar atos administrativos omissivos ou comissivos que possam causar danos ao meio ambiente. 5. Pode ser proposta ação popular ante a omissão do Estado em promover condições de melhoria na coleta do esgoto da Penitenciária Presidente Bernardes, de modo a que cesse o despejo de elementos poluentes no Córrego Guarucaia (obrigação de não fazer), a fim de evitar danos ao meio ambiente. (...). (STJ, Relator: Ministro CASTRO MEIRA, Data de Julgamento: 04/10/2007, T2 - SEGUNDA TURMA).

${ }^{21}$ Lei que regula a ação popular 
Qualquer cidadão ${ }^{22}$, portanto, está legitimado para propor ação popular ambiental. Além disso, "não é nenhum excesso entender que todos os habitantes do País, brasileiros e estrangeiros (art. $5^{\circ}$, caput), estão legitimados a utilizar a "ação popular" ambiental" (MACHADO, 158).

Outro instrumento processual de grande importância na defesa das águas é a "ação civil pública", que tem por objetivo proteger além do meio ambiente, o consumidor e os bens e interesses de valor artístico, estético, histórico, paisagístico e turístico. Ou seja, estar-se-á diante de interesses difusos e coletivos, conforme descreve a Constituição brasileira estabeleceu em seu artigo 129, inciso III.

Nessa direção, este mesmo dispositivo constitucional estabelece como função institucional do Ministério Público promover a "ação civil pública" para proteger o meio ambiente. Portanto, o Ministério Público tornou-se protagonista na defesa das águas.

A ação civil pública está regida pela Lei 7.347, de 24 de julho de 1985, e seu art. $5^{\circ}$ legitima também a propor a ação principal e a ação cautelar: (...) II - a Defensoria Pública; III - a União, os Estados, o Distrito Federal e os Municípios; IV - a autarquia, empresa pública, fundação ou sociedade de economia mista; V - a associação que, concomitantemente: a) esteja constituída há pelo menos 1 (um) ano nos termos da lei civil; b) inclua, entre suas finalidades institucionais, a proteção ao patrimônio público e social, ao meio ambiente, ao consumidor, à ordem econômica, à livre concorrência, aos direitos de grupos raciais, étnicos ou religiosos ou ao patrimônio artístico, estético, histórico, turístico e paisagístico.

Com efeito, quando se fala em ação judicial tem-se, de pronto, aquele direito subjetivo que todos têm de pedir ao Poder Judiciário a defesa de interesses próprios.

\footnotetext{
${ }^{22}$ A legitimidade ativa para a propositura da ação popular em defesa do ambiente é conferida apenas àquele que ostente a condição de cidadão, ou seja, a pessoa física no pleno gozo de seus direitos políticos, o eleitor.
}

A ação popular, bem como a ação civil pública, rompem com essa definição tradicional, já que o escopo destas ações é tutelar não interesse particular, mas, isto sim, interesses coletivos pertencentes à sociedade.

Há ainda para considerarmos, nesta quadra, a possibilidade de impetração de mandado de segurança coletivo, nos termos do artigo $5^{\circ}$, LXX, da Constituição brasileira, e do artigo 21 da Lei $12.016 / 2009$, bem como da chamada ação direta de inconstitucionalidade de lei ou ato normativo, prevista no artigo 103 da Constituição brasileira e regulamentada pela Lei 9.868 , de 10 de novembro de 1999.

A ação direta de inconstitucionalidade tem sido utilizada com frequência na impugnação de normas contrárias ao disposto no artigo 225 da Constituição brasileira, e os legitimados para sua propositura são: i) o Presidente da República; ii) a Mesa do Senado Federal; iii) a Mesa da Câmara dos Deputados; iv) a Mesa de Assembleia Legislativa ou da Câmara Legislativa do Distrito Federal; v) o Governador de Estado ou do Distrito federal; vi) o Procurador-Geral da República; vii) o Conselho Federal da Ordem dos Advogados do Brasil; viii) partido político com representação no Congresso Nacional; ix) confederação sindical ou entidade de classe de âmbito nacional.

De se registrar ainda que, de acordo com o artigo 102, inciso I, $a$, da Constituição brasileira, a ação direta de inconstitucionalidade somente pode versar sobre a constitucionalidade de lei ou ato normativo federal ou estadual. Portanto, uma lei municipal que afronte o artigo 225 da Constituição brasileira não poderá ser objeto de exame no âmbito da ação em análise.

No tocante aos nos delitos ambientais, a Lei Nacional $n^{\circ} 9.605$, de 12 de fevereiro de $1998^{23}$ estabelece sanções

\footnotetext{
23 Dispõe sobre as sanções penais e administrativas derivadas de condutas e atividades lesivas ao meio ambiente, e dá outras providências.
} 


\section{de ordem criminal a quem praticar crimes ambientais:}

Art. $2^{\mathbf{0}}$ Quem, de qualquer forma, concorre para a prática dos crimes previstos nesta Lei, incide nas penas a estes cominadas, na medida da sua culpabilidade, bem como o diretor, o administrador, o membro de conselho e de órgão técnico, o auditor, o gerente, o preposto ou mandatário de pessoa jurídica, que, sabendo da conduta criminosa de outrem, deixar de impedir a sua prática, quando podia agir para evitá-la.

Art. $3^{\mathbf{o}}$ As pessoas jurídicas serão responsabilizadas administrativa, civil e penalmente conforme o disposto nesta Lei, nos casos em que a infração seja cometida por decisão de seu representante legal ou contratual, ou de seu órgão colegiado, no interesse ou benefício da sua entidade.

Parágrafo único. A responsabilidade das pessoas jurídicas não exclui a das pessoas físicas, autoras, coautoras ou partícipes do mesmo fato.

Art. $4^{\mathbf{0}}$ Poderá ser desconsiderada a pessoa jurídica sempre que sua personalidade for obstáculo ao ressarcimento de prejuízos causados à qualidade do meio ambiente".

Especificamente em relação às águas, assim estabelece a referida lei:

Art. 15. São circunstâncias que agravam a pena, quando não constituem ou qualificam o crime:

I - reincidência nos crimes de natureza ambiental;

II - ter o agente cometido a infração:

j) em épocas de seca ou inundações;

Art. 33. Provocar, pela emissão de efluentes ou carreamento de materiais, o perecimento de espécimes da fauna aquática existentes em rios, lagos, açudes, lagoas, baías ou águas jurisdicionais brasileiras:

Pena - detenção, de um a três anos, ou multa, ou ambas cumulativamente.

Parágrafo único. Incorre nas mesmas penas:

I - quem causa degradação em viveiros, açudes ou estações de aquicultura de domínio público;

II - quem explora campos naturais de invertebrados aquáticos e algas, sem licença, permissão ou autorização da autoridade competente;

III - quem fundeia embarcações ou lança detritos de qualquer natureza sobre bancos de moluscos ou corais, devidamente demarcados em carta náutica.

Art. 53. Nos crimes previstos nesta Seção, a pena é aumentada de um sexto a um terço se:
I - do fato resulta a diminuição de águas naturais, a erosão do solo ou a modificação do regime climático;

Art. 54. Causar poluição de qualquer natureza em níveis tais que resultem ou possam resultar em danos à saúde humana, ou que provoquem a mortandade de animais ou a destruição significativa da flora:

Pena - reclusão, de um a quatro anos, e multa.

$\$ 2^{\circ}$ Se o crime:

I - tornar uma área, urbana ou rural, imprópria para a ocupação humana;

III - causar poluição hídrica que torne necessária a interrupção do abastecimento público de água de uma comunidade;

V - ocorrer por lançamento de resíduos sólidos, líquidos ou gasosos, ou detritos, óleos ou substâncias oleosas, em desacordo com as exigências estabelecidas em leis ou regulamentos:

Pena - reclusão, de um a cinco anos.

$\$ 3^{\circ}$ Incorre nas mesmas penas previstas no parágrafo anterior quem deixar de adotar, quando assim o exigir a autoridade competente, medidas de precaução em caso de risco de dano ambiental grave ou irreversível.

Art. 55. Executar pesquisa, lavra ou extração de recursos minerais sem a competente autorização, permissão, concessão ou licença, ou em desacordo com a obtida:

Pena - detenção, de seis meses a um ano, e multa.

Parágrafo único. Nas mesmas penas incorre quem deixa de recuperar a área pesquisada ou explorada, nos termos da autorização, permissão, licença, concessão ou determinação do órgão competente.

Art. 56. Produzir, processar, embalar, importar, exportar, comercializar, fornecer, transportar, armazenar, guardar, ter em depósito ou usar produto ou substância tóxica, perigosa ou nociva à saúde humana ou ao meio ambiente, em desacordo com as exigências estabelecidas em leis ou nos seus regulamentos:

Pena - reclusão, de um a quatro anos, e multa.

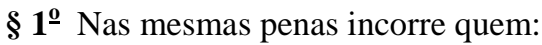

I - abandona os produtos ou substâncias referidos no caput ou os utiliza em desacordo com as normas ambientais ou de segurança;

II - manipula, acondiciona, armazena, coleta, transporta, reutiliza, recicla ou dá destinação final a resíduos perigosos de forma diversa da estabelecida em lei ou regulamento. 
$\S 2^{\circ}$ Se o produto ou a substância for nuclear ou radioativa, a pena é aumentada de um sexto a um terço.

$\$ 3^{\circ}$ Se o crime é culposo:

Pena - detenção, de seis meses a um ano, e multa.

Art. 58. Nos crimes dolosos previstos nesta Seção, as penas serão aumentadas:

I - de um sexto a um terço, se resulta dano irreversível à flora ou ao meio ambiente em geral;

II - de um terço até a metade, se resulta lesão corporal de natureza grave em outrem; III - até o dobro, se resultar a morte de outrem.

Parágrafo único. As penalidades previstas neste artigo somente serão aplicadas se do fato não resultar crime mais grave.

Art. 60. Construir, reformar, ampliar, instalar ou fazer funcionar, em qualquer parte do território nacional, estabelecimentos, obras ou serviços potencialmente poluidores, sem licença ou autorização dos órgãos ambientais competentes, ou contrariando as normas legais e regulamentares pertinentes:

Pena - detenção, de um a seis meses, ou multa, ou ambas as penas cumulativamente.

Art. 61. Disseminar doença ou praga ou espécies que possam causar dano à agricultura, à pecuária, à fauna, à flora ou aos ecossistemas:

Pena - reclusão, de um a quatro anos, e multa.

Como se vê, a Lei 9.601/1998 estabelece penas de seis meses a cinco anos, podendo estas serem aumentadas de um sexto a um terço se a contaminação se der por produto ou substância nuclear ou radioativa.

Seja como for, embora vigente e aplicável à espécie, a resposta penal à degradação das águas não é tão intimidadora e repressiva como poder-se-ia esperar. E em muitos casos, não se revela sequer instrumento de inibição de conduta.

Entretanto, o Decreto Federal $n^{\text {o }} 6.514^{24}$, de 22 de julho de 2008, estabelece mecanismo mais efetivo de proteção aos recursos hídricos quando determina aplicação de multa pecuniária que pode atingir $\mathrm{o}$ valor $\mathrm{de}$

\footnotetext{
${ }^{24}$ Dispõe sobre as infrações e sanções administrativas ao meio ambiente, estabelece o processo administrativo federal para apuração destas infrações, e dá outras providências.
}

$\mathrm{R} \$$ 50.000.000,00 (cinquenta milhões de reais):

Art. 61. Causar poluição de qualquer natureza em níveis tais que resultem ou possam resultar em danos à saúde humana, ou que provoquem a mortandade de animais ou a destruição significativa da biodiversidade:

Multa de: $\mathrm{R} \$ 5.000,00$ (cinco mil reais) a R\$ 50.000.000,00 (cinquenta milhões de reais).

Art. 62. Incorre nas mesmas multas do art. 61 quem:

III - causar poluição hídrica que torne necessária a interrupção do abastecimento público de água de uma comunidade.

$\mathrm{Na}$ sequência, vejamos, ainda, que nos delitos ambientais o Ministério Público promoverá a ação penal pública incondicionada, nos termos do artigo $26 \mathrm{da}$ Lei 9.601/1998. Trata-se, portanto, de importante instrumento colocado à disposição do Ministério Público na defesa das águas contra atividades criminosas poluidoras.

\section{TUTELA EXTRAJUDICIAL DAS ÁGUAS}

Além das tutelas judiciais mencionadas, há ainda em nosso ordenamento jurídico a previsão de meios extrajudiciais de defesa das águas. E começamos destacando o "inquérito civil", que é procedimento de natureza investigatória instaurado e presidido de maneira unilateral pelo Ministério Público, nos termos do artigo 12, inciso III, da Constituição brasileira, e artigos $8^{\circ}$ e $9^{\circ}$ da Lei federal $n^{\circ}$ 7.347/85 (Lei da Ação Civil Pública).

$\mathrm{O}$ inquérito civil destina-se a apurar a ocorrência de danos efetivos ou potenciais a direitos ou interesses difusos, coletivos ou individuais homogêneos ou outros que lhe incumba, como é o caso das águas, servindo de instrumento preparatório para o exercício de suas atribuições constitucionais, nos termos do artigo 129 da Constituição brasileira.

Além do inquérito civil, há ainda o "inquérito policial", que é procedimento administrativo de competência do delegado de polícia, destinado a apurar as 
circunstâncias, a materialidade e a autoria de infrações penais, nos termos dos artigos $4^{\circ}$ a 23 do Código de Processo Penal brasileiro. Trata-se, portanto, de importante instrumento de investigação e preparação da ação penal em matéria ambiental.

Com efeito, nos termos do artigo 39, $\S 5^{\circ}$, do Código de Processo Penal brasileiro, o inquérito policial não é indispensável, podendo o Ministério Público promover a ação penal em matéria ambiental com fundamento em outras provas, como é o caso do inquérito civil.

O inquérito policial poderá se deflagrado de ofício pela autoridade policial assim que tiver notícia do crime ambiental ou por representação de qualquer cidadão, bem como por requisição do juiz ou do Ministério Público.

Outro meio extrajudicial de proteção às águas é o "compromisso de ajustamento de conduta", nos termos do artigo $5^{\circ}, \S 6^{\circ}$, da Lei federal $n^{\circ} 7.347 / 85$ (Lei da Ação Civil Pública). Trata-se de verdadeira transação entre as partes, mediante cominações, e tem eficácia de titulo executivo extrajudicial. Ou seja, se houver descumprimento do que fora transacionado, poderá o órgão legitimado provocar o Poder Judiciário, exigindo o cumprimento integral do acordo.

Portanto, por meio do compromisso de ajustamento de conduta evita-se um longo e desgastante embate judicial, o qual nem sempre resolve a contento as questões ambientais que lhe são submetidas.

Quanto à legitimidade para aceitar a espécie de transação, o artigo $5^{\circ}, \S 6^{\circ}$, da Lei federal $\mathrm{n}^{\circ} 7.347 / 85$, confere essa possibilidade àqueles legitimados à propositura da ação civil pública, com exceção das associações, já que não se trata de "órgão público".

É possível ainda a defesa extrajudicial das águas por meio de "audiência pública", que é instrumento para a coleta de provas, dados, informações ou esclarecimentos de situações das quais decorra ou possa decorrer lesão. A audiência pública tem sido muito utilizada pelos diversos órgãos da que compõe a Administração Pública direta e indireta ou fundacional, bem como as sociedades de economia mista e as empresas públicas.

Por fim, destacam-se as "recomendações" do Ministério Público, nos termos do artigo 27, parágrafo único, inciso IV, da Lei federal $\mathrm{n}^{\circ} 8.625$, de 12 de fevereiro de 1993 (LONMP), e artigo 6, da LC $\mathrm{n}^{\circ} 75$, de 25 de maio de 1993 (LONMPU).

A recomendação, como adverte Édis Milaré (MILARÉ, pg. 1456), "é instrumento destinado à orientação de órgãos públicos ou privados, para que sejam cumpridas normas relativas a direitos e deveres assegurados ou decorrentes das Constituições Federal $e$ Estadual e serviços de relevância pública e social".

Além disso, afigura-se "como uma medida salutar, administrada mais com o propósito da vacina do que com a magia do remédio. Brota de um pressuposto mais otimista: a crença de que a orientação, o conselho, a advertência possuem uma força intrínseca reformadora provida de luz capaz de desnudar as reais intenções dos desonestos e, quando partem de pessoas ou instituições de reconhecida autoridade moral, não há como ser ignorada por gente de bem ${ }^{, 25}$.

\section{CONCLUSÕES}

Embora não seja nenhuma novidade, pode-se concluir neste trabalho que, apesar de o Brasil ser privilegiado com grandes reservas de recursos hídricos em seu território, a verdade é que, ao longo das últimas décadas, estar-se-á colocando em risco o seu maior patrimônio natural: a água doce. E se não houver mudanças concretas e efetivas no uso e reuso das

\footnotetext{
${ }^{25}$ Raul de Mello Franco Jr. A importância do instituto da "recomendação" na tutela do patrimônio público e social. Tese aprovada no I Congresso do Patrimônio Público e Social do Ministério Público do Estado de São Paulo, realizado em São Paulo, entre 18 e 21.08.2010 apud Édis Milaré, Direito do Ambiente, $9^{\mathrm{a}}$ edição, editora RT, 2014, pg. 1456.
} 
águas, bem como a preservação do meio ambiente, em pouco tempo o resultado será catastrófico para todos. E quando esse tempo chegar [e não está muito longe], quiçá a discussão acerca da sobrevivência da espécie humana receba mais atenção dos líderes mundiais da que hoje se constata. Aliás, as discussões econômicas ocupam grande parte das agendas dos governantes que, por sua vez, deveriam estar debruçados sobre estudos e propostas de melhorias e proteções ao meio ambiente. Com efeito, de que adiantará toda a riqueza material do homem se no futuro não houver vida para usufrui-la?

No Brasil, a grave seca hoje vivenciada no Sudeste e Centro-Oeste e o excesso de chuvas e enchentes em outras partes do País deixa evidente a necessidade premente de se implementar políticas sérias de preservação do meio ambiente, notadamente das águas.

Nessa ordem, racionamentos no fornecimento de água e até mesmo de energia elétrica têm se tornado frequente para milhões de pessoas no Brasil, a exemplo do que está acontecendo hoje em estados como São Paulo e Rio de Janeiro.

\section{REFERÊNCIAS}

DE CARLI, Ana Alice- A Água e Seus Instrumentos de Efetividade, Editora Millennium, 2013.

BARLOW, MAUDE e CLARKE, TONY. Ouro Azul: como as grandes corporações estão se apoderando da água doce do nosso planeta. Tradução de Andreia Nastri. Tradução de atualizações de Natália Coutinho Mira de Assumpção. São Paulo: Editora M. Books do Brasil, 2003.

BRASIL, Constituição da República Federativa do Brasil (1988). Vade Mecum Acadêmico de Direito Rideel. Organização: Anne Joyce Angher. $16^{\circ}$ edição. São Paulo: Rideel, 2013.

BRASIL, Supremo Tribunal Federal. Recurso Extraordinário $\mathrm{n}^{\circ}$ 596723/RS,
A verdade é que, o Brasil, está vulnerável e despreparado para lidar com todas essas mudanças climáticas.

Com efeito, não se pode conceber a permanência desse estado atual de inércia ambiental em relação às águas, ao meio ambiente. E como já se disse anteriormente, as gerações atuais têm a obrigação de conhecer e, sobretudo colocar em prática as tutelas legais de proteção aos ecossistemas, notadamente das águas. Embora sejam os principais atores nesse palco, não cabe apenas aos governantes a proteção das águas, do meio ambiente. Essa tarefa, por certo, pertence a toda sociedade, uma vez que a sobrevivência da espécie humana é que de fato está em pauta.

Assim, além de todos os cuidados e deveres que se deve ter, a legislação nacional ainda estabelece meios de proteção às águas, aos ecossistemas. E neste trabalho pode-se destacar instrumentos judiciais e extrajudiciais colocados à disposição de toda a sociedade, bem como da Administração Pública direta, indireta e fundacional, na defesa das águas, bem como do meio ambiente como um todo.

Relator: Ministro EROS GRAU, Data de Julgamento: 17/11/2009, Data de Publicação: DJe-228 - 04/12/2009. Disponível em: www.stf.gov.br. Acesso em: 11.03.2015.

.Agravo em Recurso Extraordinário $\mathrm{n}^{\circ}$ 805414/RS, Relator: Ministro GILMAR MENDES, Data de Julgamento: 15/04/2014, Data de Publicação: DJe077/24/04/2014. Disponível em: www.stf.gov.br. Acesso em: 11.03.2015.

.Medida Cautelar na Ação Direta de Inconstitucionalidade - Pleno, ADIn/MC 3540-1, Relator: Ministro Celso de Mello Disponível em: www.stf.gov.br. Acesso em: 11.03.2015.

BRASIL, Superior Tribunal de Justiça. Recurso Especial $n^{\circ}$ 994120/RS 
2007/0234852-0, Relator: Ministro HERMAN BENJAMIN, Data de Julgamento: 25/08/2009, T2 - Data de Publicação: DJe 27/04/2011). Disponível em: www.stj.gov.br. Acesso em: 11.03.2015.

FRANCO JÚNIOR, Raul de Mello. A importância do instituto da "recomendação" na tutela do patrimônio público e social. Tese aprovada no I Congresso do Patrimônio Público e Social do Ministério Público do Estado de São Paulo, realizado em São Paulo, entre 18 e 21.08.2010 apud Édis Milaré, Direito do Ambiente, $9^{a}$ edição, editora RT, 2014, pg. 1456.

MACHADO, Paulo Affonso Leme, Direito Ambiental Brasileiro, 22 $2^{\mathrm{a}}$ edição, ed. Malheiros, 2014.

MARTINS DA SILVA, Américo Luís, Direito do Meio Ambiente e dos Recursos Naturais, v. 3, Editora RT, 2006.

MILARÉ, Édis. Direito do Ambiente. $9^{\text {a }}$ edição, ed. Revista do Tribunais, 2014.

POMPEU, Cid Tomanik, Apub DE CARLI, Ana Alice, A Água e Seus Instrumentos de Efetividade, pg. 53/54, Editora Millennium, 2013;

Águas Doces no Direito Brasileiro. In: REBOUÇAS, Aldo da Cunha; BRAGA, Benedito; TUNDISI, José Galizia (Org). Águas doces no Brasil: capital ecológico, uso e conservação. 2. Ed. São Paulo: Escrituras, 2002.

SHIKLOMANOV, I.A., SHIKLOMANOV, A.I., LAMMERS, R.B., PETERSON, B.J. \& VOROSMARTY, C.J. 2000. The dynamics of river water infl ow to the Arctic Ocean. In: Lewis, E.L., Jones, E.P., Prowse, T.D. \& Wadhams, P. (eds) The freshwater budget of the Arctic Ocean. Kluwer Academic Publishers, Dordrecht. p. 281-296 